\title{
Noninvasive ventilation in patients with acute respiratory distress syndrome
}

\author{
Kailei Du(10 \\ This comment refers to the article available at https://doi.org/10.1186/s13054-019-2575-6.
}

To the Editor:

The benefits of noninvasive ventilation (NIV) in acute respiratory distress syndrome (ARDS) have long been debated. In a recent well-designed trial, $\mathrm{He}$ et al. [1] found that compared to standard oxygen therapy, NIV in mild ARDS patients did not reduce the intubation rate. We would like to add some comments. First, even though a targeted tidal volume $\left(V_{\mathrm{T}}\right)$ was set, adequate control of the $V_{\mathrm{T}}$ was difficult during NIV. In an observational study [2], Carteaux et al. reported that despite setting the targeted $V_{\mathrm{T}}$ at $6-8 \mathrm{~mL} / \mathrm{kg}$, the actual $V_{\mathrm{T}}$ was $9.8 \mathrm{~mL} / \mathrm{kg}$ during application ( $75 \%$ of patients had $V_{\mathrm{T}}>8 \mathrm{~mL} / \mathrm{kg}$ ). Similarly, the LUNG-SAFE study [3] also reported that the mean $V_{\mathrm{T}}$ was $8.73 \mathrm{~mL} / \mathrm{kg}$ in ARDS patients managed with NIV. Physiologically, $V_{\mathrm{T}}$ during NIV is the consequence of both the ventilation-inspiratory pressure support and the spontaneous respiratory muscle activity. Thus, even with the inspiratory pressure set at a low level, patients may still spontaneously breathe with a high $V_{\mathrm{T}}$ because of a strong respiratory effort to alleviate tachypnea/dyspnea. Second, differences in ARDS severity remain an important cause of inconsistent findings. In a propensity-matched analysis, Bellani et al. [3] found that in a group of ARDS patients with $\mathrm{PaO}_{2} / \mathrm{FIO}_{2}<150 \mathrm{mmHg}$, the mortality of the NIV group was significantly higher than that of the invasive ventilation group. This may be due to the fact that tidal hyperinflation during NIV may be more significant as the lung in patients with severe ARDS is stiffer, which is a significant risk factor for ventilation-induced lung injury. In the study by $\mathrm{He}$ et al. [1], only patients with mild ARDS were investigated. However, Shen et al. [4] found that the benefit of low $V_{\mathrm{T}}$ ventilation is more significant in mild than in severe ARDS. Thus, whether NIV should be considered when treating ARDS still requires investigation. Third, there are different NIV approaches. In 2016, Patel et al. [5] showed that the use of helmet NIV resulted in a

\section{Correspondence: dkldyrm@163.com}

Intensive Care Unit, Affiliated Dongyang Hospital of Wenzhou Medical University, NO. 60 Wuning West Road, Dongyang 322100, China significant reduction in the rate of intubation when compared to mask (8/44 vs. $24 / 39, p<0.001)$. However, in the helmet group, the positive end-expiratory pressure (PEEP) was significantly higher $(8[5.0-10.0]$ vs. 5.1 [5.0-8.0], $p=$ 0.006) and the supported pressure was lower (8 [5.6-10.0] vs. $11.2[10.0-14.5], p<0.001)$ than in the mask group. Higher PEEP and lower pressure support are supposed to be associated with lower driving pressure. Thus, whether the benefit of helmet NIV was a result of a more protective ventilation strategy remains unclear. Finally, we suggest that further studies should incorporate mechanical indexes (low $V_{\mathrm{T}}$, driving pressure, etc.) into NIV application to obtain more positive results.

\author{
Acknowledgements \\ None. \\ Authors' contributions \\ $\mathrm{KD}$ is responsible for study design writing, and this manuscript is approved \\ by $K D$. \\ Funding \\ None.
}

Availability of data and materials

Not applicable.

Ethics approval and consent to participate

Not applicable.

Consent for publication

Not applicable.

Competing interests

The authors declare that they have no competing interests.

Received: 15 October 2019 Accepted: 7 November 2019

Published online: 15 November 2019

\footnotetext{
References

1. He H, Sun B, Liang L, Li Y, Wang H, Wei L, Li G, Guo S, Duan J, Li Y, et al. A multicenter RCT of noninvasive ventilation in pneumonia-induced early mild acute respiratory distress syndrome. Crit Care. 2019;23(1):300.

2. Carteaux G, Millan-Guilarte T, De Prost N, Razazi K, Abid S, Thille AW, Schortgen F, Brochard L, Brun-Buisson C, Mekontso Dessap A. Failure of noninvasive ventilation for de novo acute hypoxemic respiratory failure: role of tidal volume. Crit Care Med. 2016;44(2):282-90.
} 
3. Bellani G, Laffey JG, Pham T, Madotto F, Fan E, Brochard L, Esteban A, Gattinoni L, Bumbasirevic V, Piquilloud L, et al. Noninvasive ventilation of patients with acute respiratory distress syndrome. Insights from the LUNG SAFE Study. Am J Respir Crit Care Med. 2017;195(1):67-77.

4. Shen Y, Cai G, Gong S, Dong L, Yan J, Cai W. Interaction between low tidal volume ventilation strategy and severity of acute respiratory distress syndrome: a retrospective cohort study. Crit Care. 2019;23(1):254.

5. Patel BK, Wolfe KS, Pohlman AS, Hall JB, Kress JP. Effect of noninvasive ventilation delivered by helmet vs face mask on the rate of endotracheal intubation in patients with acute respiratory distress syndrome: a randomized clinical trial. JAMA. 2016;315(22):2435-41.

\section{Publisher's Note}

Springer Nature remains neutral with regard to jurisdictional claims in published maps and institutional affiliations. 